\title{
Shedding Rates and SeroPrevalence of Brucella melitensis in Lactating Goats of Shahrekord, Iran
}

\author{
Azizollah Ebrahimi ${ }^{1, *} ;$ Jalal Sheykh kanluye Milan ${ }^{2}$; Mohamad Reza Mahzoonieh ${ }^{1}$; Khadijeh \\ Khaksar $^{3}$ \\ ${ }^{1}$ Institute of Zoonotic Diseases, Shahrekord University, Shahrekord, IR Iran \\ ${ }^{2}$ School of Veterinary Sciences, Shahrekord University, Shahrekord, IR Iran \\ 3 Office of Veterinary Organization, Shahrekord, IR Iran \\ ${ }^{*}$ Corresponding authors: Azizollah Ebrahimi, School of Veterinary Sciences, Shahrekord University, P.O.Box: 115, Shahrekord, IR Iran. Tel: +98-3814424427; +98-9133197980, Fax: +98- \\ 3814424427, E-mail: A_kahrizsangi@yahoo.com
}

Received: December 1, 2012; Revised: February 20, 2013; Accepted: March 10, 2013

\begin{abstract}
Background: Brucellosis remains a major worldwide zoonosis. Caprine brucellosis is a significant problem for both public health and animal production. Brucella melitensis causes disease in goats, sheep, humans, and occasionally cattle. Transmission is by ingestion or contact with infected materials, vaginal discharge, or milk.

Objectives: The current study aimed to determine the rate of B. melitensis seropositives and its probable shedding in lactating goats from flocks in Shahrekord district, Iran.

Materials and Methods: In the current study, 1080 samples of milk, blood and vaginal swabs of 360 lactating goats (three samples from each animal) were randomly collected from 12 flocks in Shahrekord district. Serums from blood samples were examined by Rose Bengal plate (RBT) test and the titre of positives determined by tube agglutination test(TAT). Vaginal swab and milk (cream and sediment) samples were cultured on Brucella agar. Brucella spp. suspected pure cultures were incubated in the same conditions and then examined by Modified Zeil-Nelson (MZN) staining, oxidase and catalase tests. Positive isolates were examined by PCR.

Results: Out of 360 serum samples, 50 (13.9\%) were positive by RBT, and six (1/66\%) were positive by TAT. Culturing of milk and vaginal samples lead to isolation of $12(3.33 \%)$ and 10 (2.77\%) Brucella spp. suspected colonies, respectively. The PCR examinations of these isolates showed that ten (2.77\%) milk and 6 vaginal swab samples (1.66\%) belonged to B. melitensis species. Eight goats (2.22\%) had positive results in RBT, culture and PCR examinations, simultaneously.

Conclusions:The regional distribution of caprine brucellosis and shedding of $B$. melitensis through vaginal secretions and milk secretions of lactating goats indicated that $50 \%$ and $83.33 \%$ of the goat flocks contained vaginal and milk shedders, respectively.

Keywords:Goats; Brucellosis; Brucella melitensis; Milk; Vagina; Serology
\end{abstract}

\section{Background}

Brucellosis is an important zoonosis causing debilitating disease in humans. Brucella species and their principal farm animal hosts are Brucella abortus (cattle), B. melitensis (goats), B. suis (pigs), and B. ovis (sheep) (1). In general, the principal manifestations of brucellosis are reproductive failures such as abortion or birth of unthrifty newborn in the female, and orchitis and epididymitis with frequent sterility in the male. Caprine brucellosis is a significant problem for both public health and animal production. B. melitensis cause disease in goats, sheep, humans, and occasionally cattle (1).

Transmission is congenital or by ingestion or contact with infected placenta, vaginal discharge, or milk. Infected goats, whether aborted or given birth normal- ly, discharged a large number of Brucella spp. in their uterine exudates and placenta (2). The majority of goats that are infected during pregnancy will excrete the organism in their milk in the subsequent lactation, and many will excrete it in all future lactations (2). Isolation of the organism from the aborted fetus, vaginal mucus, or milk is the common laboratory procedure applied in diagnosis. The conventional serological tests for the diagnosis of $B$. melitensis are agglutination, CFT, and the Rose Bengal or card tests. Conventional serological tests will not differentiate infection with different species of Brucella. The Rose Bengal test has excellent specificity and high sensitivity (3).

PCR assay is a rapid and sensitive technique for diagnosis of brucellosis compared to serum agglutination test (SAT) method. However it is more valuable when coupled with conventional methods (4). The preva-

Implication for health policy makers/practice/research/medical education

There is at least one vaginal or milk shedders of Brucella melitensis in each goat flocks of the region.

Copyright (C) 2014,Ahvaz Jundishapur University of Medical Sciences; Published by Kowsar Corp. This is an open-access article distributed under the terms of the Creative Commons Attribution License, which permits unrestricted use, distribution, and reproduction in any medium, provided the original work is properly cited. 
lence of brucellosis is increasing in many developing countries (5). Several authors have reported the prevalence of brucellosis in both animals and humans in various parts of Iran (6-9). However, information is scarce on brucellosis in goat flocks in Iran. The current study was conducted to evaluate status of caprine brucellosis by serological tests and also isolation and identification of $B$. melitensis from milk samples and vaginal swabs of lactating goats in Shahrekord district, west of Iran.

\section{Objectives}

The current study aimed to determine the rate of $B$. melitensis seropositives and its probable shedding in lactating goat flocks in Shahrekord district, Iran.

\section{Materials and Methods}

\subsection{Sample Collection and Serological Tests}

From March to June 2012, 1080 samples of milk, blood and vaginal swab of 360 lactating goats (three samples from each animal) were randomly collected from 12 flocks rearing in different regions of Shahrekord. Based on owners statements all flocks had been vaccinated against brucellosis, however, some owners feared to say that their flocks were unvaccinated in case of ignored vaccination. Ten flocks composed of both sheep and goat populations. The samples transferred to the microbiology laboratory of institute of zoonotic diseases, Shahrekord University in sterile tubes that in the case of vaginal swabs contained $2 \mathrm{~mL}$ of Tryptic Soy Broth (TSB) (Merck, Germany). Serums from blood samples were examined by Rose Bengal Plate test (RBT) and the titers of positive samples were determined by tube agglutination test (TAT). RBT and TAT antigens were purchased from Razi Serum and Vaccine Research Institute and Behine Parvar Parsian Institute, Tehran, respectively.

\subsection{Milk and Vaginal Swab Cultures}

Samples of vaginal swab and milk (cream and sediment) were cultured on Brucella agar plates that contained 5\% bovine blood, bacitracin (25 IU $/ \mathrm{mL})$, Polymyxin B (6 IU/mL) and incubated for 72 hours at $37^{\circ} \mathrm{C}(10)$. Brucella suspected colonies were pure cultured and after incubation in the same conditions and then examined by modified Zeil-Nelson (MZN) staining and oxidase and catalase tests (10). Modified Zeil-Nelson, oxidase and catalase positive isolates were cultured in TSB medium and stored for further examinations.

\subsection{PCR Examination}

The crude DNA was extracted by Quigley and Holmes method (11) from suspected Brucella spp. In brief, a few colonies of bacteria were suspended in $1 \mathrm{~mL}$ of sterile water and boiled for 15-40 seconds and after a low-speed centrifugation the supernatants were used as a DNA source. The applied B. melitensis specific primers have been previously described by Bricker and Halling (12).

The sequences of the forward primer was 5'-AAATCGCGTCCTTGCTGGTCTGA-3' (B. melitensis specific primer) and the reverse was 5'-TGCCGATCACTTAAGGGCCTTCAT-3' (IS711-specific primer). PCR assay was performed in a final volume of $25 \mu \mathrm{L}$ mixture containing: 10 times PCR buffer $(50 \mathrm{mM}$ $\mathrm{KCl}, 10 \mathrm{mM}$ Tris-HCl pH = 8.3), $1.50 \mu \mathrm{L} \mathrm{MgCl}_{2}(50 \mathrm{mM})$, 0.25 of each deoxynucleotide triphosphate $(10 \mathrm{mM})$, $1 \mu \mathrm{L}$ of each primer, Taq DNA polymerase ( $5 \mathrm{U} / \mu \mathrm{L}$, Cinnagen, Iran) and $2 \mu \mathrm{L}$ of bacterial DNA as the template. The amplifications were carried out in a Corbett thermo cycler, as follows: initial denaturation at $94^{\circ} \mathrm{C}$ for 1 minute followed by 35 cycles of $95^{\circ} \mathrm{C}$ for 1.15 minutes, $55^{\circ} \mathrm{C}$ for 2 minutes and $72^{\circ} \mathrm{C}$ for 2 minutes with a final extension at $72^{\circ} \mathrm{C}$ for 5 minutes.

The products were analyzed by electrophoresis through a $1.5 \%(\mathrm{w} / \mathrm{vol})$ agarose gel, after which the gel was stained with $0.5 \mu \mathrm{g} / \mathrm{mL}$ Ethidium bromide, and DNA fragments were visualized by a UV Transilluminator. Positive and negative controls of PCR were included in all experiments. B. melitensis Rev1 strain (Razi Institute, Iran) was used as the positive and deionized double distilled water as the negative control. Negative control, containing all the reagents but lacking template DNA was processed exactly as previously described to monitor for contamination with Brucella DNA, which was negative in all experiments.

\section{Results}

Overall, out of 360 serum samples, 50 (13.9\%) were positive by RBT out of which six (1.66\%) and 19 (5.27\%) were positive (titers of 1.40 or higher) and suspicious by TAT, respectively. Culturing 360 milk and 360 vaginal samples led to isolation of 12 (3.33\%) and 10 (2.77\%) suspected Brucella spp. colonies, respectively (22 isolates, in total). Details are summarized in Table 1. Eight goats $(2.22 \%)$ were positive in RBT, culture and PCR examinations, simultaneously. Test results of these isolates by PCR method showed that 10 (2.77\%) milk and six vaginal swab samples (1.66\%) belonged to $B$. melitensis, Figure 1. In six out of 12 studied flocks (50\%) there were at least one vaginal excretors while for milk this number was 10 (83.33\%), details are summarized in Table 2. 
Ebrahimi A et al.

Table 1. Results of Rose Bengal Plate Test, Milk Culture and PCR of Suspected Isolated Brucella spp. Colonies From Milk and Vaginal Swab Cultures of 360 Lactating Goats in Shahrekord District ${ }^{\mathrm{a}}$, $^{\mathrm{b}}$

\begin{tabular}{|c|c|c|c|c|c|c|}
\hline \multirow[t]{2}{*}{ Methods } & \multicolumn{2}{|c|}{ Vaginal Swab } & \multicolumn{2}{|c|}{ Milk } & \multicolumn{2}{|c|}{ Serum } \\
\hline & Positive, No. (\%) & Negative, No. (\%) & Positive, No. (\%) & Negative, No. (\%) & Positive, No. (\%) & Negative, No. (\%) \\
\hline Culture & $10(2.77)$ & $350(97.23)$ & $12(3.33)$ & $348(96.67)$ & & \\
\hline RBT & & & & & $50(13.9)$ & $310(86.1)$ \\
\hline TAT & & & & & $6(1.66)$ & $44(12.22)$ \\
\hline PCR & $6(1.66)$ & $4(1.11)$ & $10(2.77)$ & $2(0.55)$ & & \\
\hline
\end{tabular}

a Abbreviations: PCR, polymerase chain reaction; RBT, Rose Bengal test; TAT, tube agglutination test.

$\mathrm{b}_{\text {TAT }} 50$ RBT positive samples; PCR of positive cultures

Figure 1. PCR Products Amplified From Brucella spp Suspected Colonies. Genomic DNAs From Bacterial Colonies Were Tested in the PCR Assay as Described in the Text

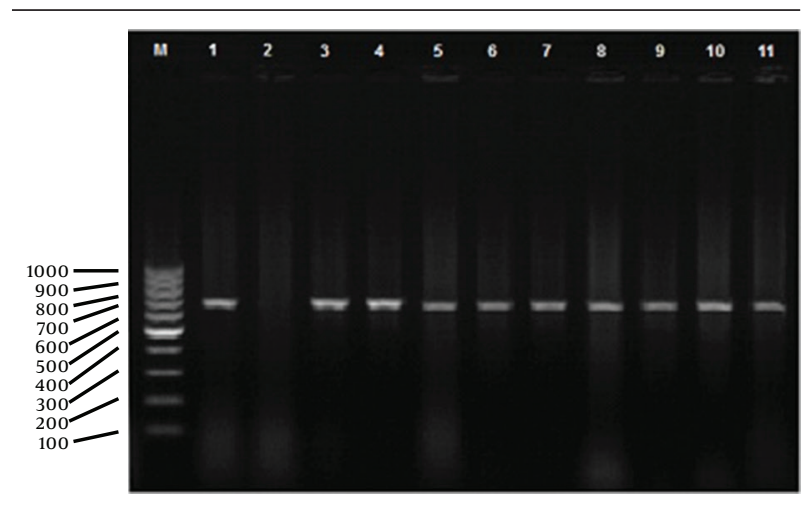

Lane M, Marker 100 bp (base pair) DNA Ladder (Fermentas, Slovenia), lane 1, Positive Control (B. melitensis, Rev 1 strain, Razi, Iran), lane 2, Negative Control (Water), lanes 3-11 Samples

Table 2. Number of Goats Excreting Brucella melitensis in Flocks of Shahrekord District ${ }^{\mathrm{a}}$

\begin{tabular}{lll}
\hline Flock Numbers & PVS & PM \\
\hline $\mathbf{1}$ & 1 & 1 \\
$\mathbf{2}$ & 1 & 1 \\
$\mathbf{3}$ & 0 & 1 \\
$\mathbf{4}$ & 0 & 1 \\
$\mathbf{5}$ & 1 & 0 \\
$\mathbf{6}$ & 0 & 0 \\
$\mathbf{7}$ & 0 & 2 \\
$\mathbf{8}$ & 0 & 1 \\
$\mathbf{9}$ & 0 & 0 \\
$\mathbf{1 0}$ & 1 & 1 \\
$\mathbf{1 1}$ & 2 & 1 \\
$\mathbf{1 2}$ & 0 & 1 \\
\hline
\end{tabular}

a Abbreviations: PM, positive milk samples; PVS, positive vaginal swabs.

\section{Discussion}

Brucellosis remains a major worldwide zoonosis (13). The study results indicated that the shedding rates of $B$. melitensis by lactating goats in Shahrekord, west of Iran, was $2.77 \%$ in milk samples and $1.11 \%$ by vaginal excretions. This rate of shedding of $B$. melitensis by goat populations in the district could potentially lead to public health and veterinary problems. The study results also showed that $50 \%$ and $83.33 \%$ of the flocks contained vaginal and milk shedder goats, respectively. Also the possibility of sheep shedders in these flocks should not be ignored. Pasteurization and boiling of milk and milk products may limit transmission of B. melitensis to human and healthy animals, but the story for vaginal excretors is different.

The selected animals were not just after lambing, so in this case disinfection of lambing sites does not seem to have a considerable effect on limiting the distribution of the bacteria to different environments. Although this method is certainly a major program to control animal brucellosis. Moreover, most of the flocks in this district have a seasonal migration pattern to neighboring provinces such as Khuzestan and Fars, which can contaminate other parts of the country. It seems that to control these shedders, development of detection and slaughter policies are the best choice but in the case of small ruminants, in Iran such policies have not been followed due to some technical and economic problems.

Moshkelani et al. (6) reported high isolation rates (16.4\%) of B. melitensis from aborted goat fetuses in Chaharmahalva-Bakhtyari province, indicating the significant role of $B$. melitensis in goat abortions in the district. From east of Iran (Birjand city) Bokaie et al. reported a 3.4\% seroprevalence for sheep and goat brucellosis (14). Zowghi and Ebadi (15) isolated B. melitensis from 0.24 and $3.4 \%$ of bovine tested milk and aborted fetus samples, respectively; the report emphasized on the role of $B$. melitensis in bovine infection, excretion in bovine milk and bovine abortions. The current study results are in line with those of Esmaieli et al., (16) indicated that $2.1 \%$ of sheep and goats in Iran are suffering from brucellosis. The current study's serological tests, RBT and TAT, showed $13.9 \%$ and $1.66 \%$ seroprevalence for caprine brucellosis, respectively. The difference between the two tests may be due to inactive brucellosis or vaccinal antibodies detect- 
ed by RBT but ignored by TAT.

There is one report from Sarab city (17), north west of Iran, that showed a $5 \%$ seroprevalence for goats in this region. The difference in these reports might be from differences in the study design, duration, variation among infected flocks, stage of infection, and variation in the sensitivity of the tests used. Brucella spp. isolation is influenced by factors such as highly fastidious growth requirement, a fewer number of viable organisms in the specimen, delay in transportation and earlier treatment with chemotherapeutics (18). The current study found that many goat farmers seemed to be unaware of the importance of hygiene and other managemental factors to prevent Brucella spp. transmission.

In conclusion the current study indicated regional distribution of caprine brucellosis and shedding rates of 1.1\% through vaginal and $2.77 \%$ through milk secretions of lactating goats, and that $50 \%$ and $83.33 \%$ of the flocks contained at least one vaginal or milk shedders, respectively. Moving these flocks should be controlled by appropriate regulations. Infected animals must be detected and slaughtered and all goats should be vaccinated against brucellosis.

\section{Acknowledgments}

None declared.

\section{Authors' Contribution}

A. Ebrahimi designed and supervised the work, also wrote the manuscript; Jalal SH. Milan and K. Khaksar carried out the study; M. Mahzonieh supervised PCR examinations, all authors read and approved the final manuscript.

\section{Financial Disclosure}

The authors declare no conflict of interests.

\section{Funding/Support}

The current study was supported by a grant from the Research affairs of Shahrekord University.

\section{References}

1. Radostitis OM, Gay CC, Blood DC, Hinchcliff KW, Gay C. Veterinary medicine: a textbook of the diseases of cattle, sheep, pigs, goats and horses. 10th edKhadoury: W B Saunders; 2000.

2. Alton GG. Brucella melitensis. In: Nielsen K, Duncan JR editors. Animal Brucellosis.. Boca Raton: CRC Press; 1994.pp. 383-409.

3. Blasco JM, Marin C, Jimenez de Bagues M, Barberan M, Hernandez A, Molina L, et al. Evaluation of allergic and serological tests for diagnosing Brucella melitensis infection in sheep. J Clin Microbiol.1994;32(8):1835-40.

4. Rastegar AL, Fallah F, Karimi A, Gachkar L, Angoti G, Sanaei A The efficacy of multiplex PCR in comparison with agglutination and ELISA in human Brucellosis diagnostic. Iran J Clin infect Dis. 2011;6:143.

5. Gwida M, Al Dahouk S, Melzer F, Rosler U, Neubauer H, Tomaso H. Brucellosis - regionally emerging zoonotic disease? Croat Med J. 2010;51(4):289-95.

6. Moshkelani S, Javaheri-Koupaei M, Fathpour H, Alirezaei M. Detection of Brucella melitensis from Aborted Caprine Fetuses in Iran. Glob Veterinaria. 2011;6(5):495-7.

7. Nikokar I, Hosseinpour M, Asmar M, Pirmohbatei S, Hakeimei F, Razavei MT. Seroprevalence of Brucellosis among high risk individuals in Guilan, Iran. J Res Med Sci. 2011;16(10):1366-71.

8. Salari MH. Seroepidemiological survey of Brucellosis among animal farmers of Yazd province. Iran J Pub Health. 2002;31(1-2):29-32.

9. Zowghi E, Ebadi A, Yarahmadi M. Isolation and identification of Brucella organisms in Iran. Iran JClin Infect Dis. 2009;3(4):185-8.

10. Alton GG. Culture media. In: Jones LM, Pietz DE editors. Laboratory techniques in brucellosis.. Geneva: WHO; 1975. pp.14-8.

11. Holmes DS, Quigley M. A rapid boiling method for the preparation of bacterial plasmids. Anal Biochem.1981;114(1):193-7.

12. Bricker BJ, Halling SM. Differentiation of Brucella abortus bv. 1, 2 , and 4, Brucella melitensis, Brucella ovis, and Brucella suis bv. 1 by PCR. J Clin Microbiol. 1994;32(11):2660-6.

13. Cutler $\mathrm{S}$, Whatmore A. Progress in understanding brucellosis. Vet Rec. 2003;153(21):641-2.

14. Bokaie S, Sharifi L, Alizadeh H. Epidemiological survey of brucellosis in human and animals in Birjand, east of Iran.J Anim Vet Adv. 2008;7(4):460-3.

15. Zowghi E, Ebadi A. Naturally occurring Brucella melitensis infection in cattle in Iran. Rev Sci Tech. 1985;4(4):811-4.

16. Esmaeili H, Partovi R, Marhamati Khamemeh B, Hamedi M, Khaji L. Evaluation of the National Sheep and Goat Brucellosis Control Program in Iran. Arak Med Univ J. 2012;14(7):9-20.

17. Akbarmehr J, Ghiyamirad M. Serological survey of brucellosis in livestock animals in Sarab City (East Azarbayjan province), Iran. Afr J Microbiol Res. 2011;5(10):1220-3.

18. Al-Talafhah AH, Lafi SQ, Al-Tarazi Y. Epidemiology of ovine brucellosis in Awassi sheep in Northern Jordan. Prevent Vet Med. 2003;60(4):297-306. 